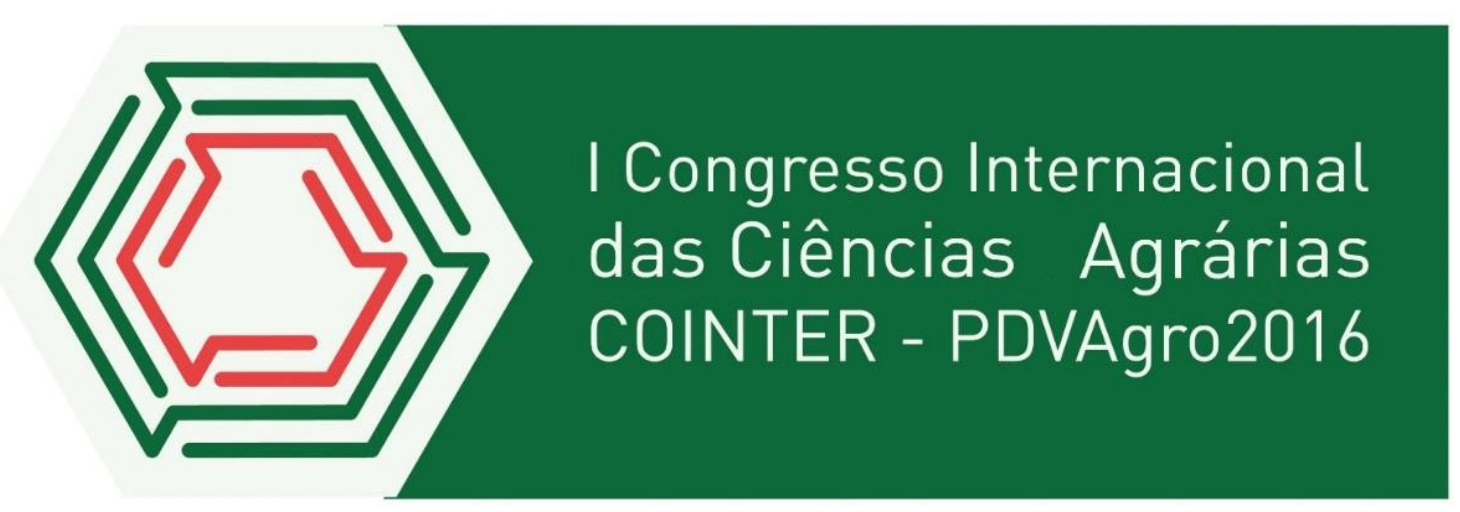

\title{
BIOMETRIA DO COQUEIRO ANÃO SUMETIDO À UTILIZAÇÃO DE BIOFERTILIZANTE LÍQUIDO COM E SEM COBERTURA DO SOLO
}

\author{
José Avelino De Queiroga Neto ${ }^{1}$; Ubiratan Matias De Queiroga Júnior ${ }^{1}$; Ériton \\ Eriberto Martins Dantas ${ }^{1}$; Andreza Monaliza Andrade Dos Santos ${ }^{1}$; Raimundo \\ Andrade $^{2}$ \\ ${ }^{1}$ Graduandos do Curso de Ciências Agrárias/DAE/UEPB, E-mail: josehatake@ bol.com.br \\ ${ }^{2}$ Prof. Doutor/Pesquisador DAE/CCHA/UEPB, E-mail raimundoandrade@uepb.edu.br
}

\section{Introdução}

No Brasil, o coqueiro é cultivado predominantemente no litoral do Nordeste, região onde se concentra as principais agroindústrias de coco; representando em 2007 segundo o Agrianual (2008), 95\% da área colhida (227.090 ha) e 79\% da produção brasileira, cerca de 1.332.584 frutos. A Bahia é o maior produtor de coco do Brasil com 629.823 frutos, seguido pelo Ceará (249.320) e Pernambuco (160.336).

Entende-se por produto orgânico aquele produzido em um sistema de produção sustentável no tempo e no espaço, mediante o manejo e a proteção dos recursos naturais, sem a utilização de produtos químicos agressivos ao homem e ao meio ambiente, mantendo-se o incremento da fertilidade e da vida dos solos e a diversidade biológica (BORGES e BETTIOL, 1997; DAROLT, 2002; SOUSA e RESENDE, 2006)

A cobertura morta também diminui a amplitude de variação da temperatura do solo, mantendo-a dentro de limites fisiológicos razoáveis. Vidal e Bauman (1996), estudando o efeito de níveis de palha de trigo no microclima do solo sob plantio direto, concluíram, entre outras coisas, que o incremento nos níveis de palha de trigo reduziu a temperatura máxima e teve pouco efeito na temperatura mínima do solo.

Objetivou-se avaliar a biometria do coqueiro anão em função da aplicação de diferentes dosagens de biofertilizante enriquecido com e sem cobertura do solo. 


\section{Fundamentação Teórica}

O coqueiro é a palmeira de maior importância sócio-econômica das regiões tropicais, gerando empregos, divisas e renda para mais de 86 países. A produção mundial de coco é de 55.037.524 t (FAO, 2006), e o continente asiático principalmente Indonésia (29\%), Filipinas (26\%) e Índia (17\%), ocupam, lugar de destaque com $72 \%$ dessa produção.

A adubação orgânica no Brasil tem aumentado graças aos elevados custos dos fertilizantes minerais nos solos intensamente cultivados na forma convencional (RODRIGUES, 1990; ORMOND et al,. 2002).

Na produção de mudas, têm-se observado efeito benéfico da adubação orgânica, sobre a qualidade das mudas, quando comparada à adubação exclusivamente mineral, sendo o esterco de curral a fonte de adubo orgânico mais utilizado pelos viveiricultores (FILGUEIRA, 2000).

O biofertilizante é o efluente pastoso resultante da fermentação da matéria orgânica, na ausência total de oxigênio atmosférico, por um determinado tempo. $\mathrm{O}$ produto é obtido da fermentação de esterco fresco de curral e água em processo anaeróbico a praticamente, custo zero, reduzindo-se assim, cerca de $80 \%$ dos gastos com insumos na propriedade (EMBRAPA,1999).

A cobertura morta também diminui a amplitude de variação da temperatura do solo, mantendo-a dentro de limites fisiológicos razoáveis. Vidal e Bauman (1996), estudando o efeito de níveis de palha de trigo no microclima do solo sob plantio direto, concluíram, entre outras coisas, que o incremento nos níveis de palha de trigo reduziu a temperatura máxima e teve pouco efeito na temperatura mínima do solo.

\section{Metodologia}

A pesquisa foi conduzida em condições de campo, no município de Belém do Brejo do Cruz/PB, localizada pelas coordenadas geográficas de $6^{0} 28^{\prime} 12^{\prime \prime}$ de latitude Sul, 37020'32" de longitude Oeste de Greenwich tendo uma altitude de 176 metros acima do nível do mar.

O delineamento experimental foi em blocos casualizados, com cinco repetições e 60 plantas experimentais, em arranjo fatorial de $6 \times 2$ totalizando 12 tratamentos. Os tratamentos serão referentes a seis doses de biofertilizante enriquecidos $[(\mathrm{D} 1=0$ 
(L/planta/vez) D2= 0,5 (L/planta/vez); D3= 1,0 (L/planta/vez); D4= 1,5 (L/planta/vez); D5= 2,0 (L/planta/vez) e 2,5 (L/planta/vez) $)$, com e sem mulch $\left(\mathrm{C}_{1}=\right.$ presença de mulch e $\mathrm{C}_{0}=$ Ausência de mulch) no crescimento vegetativo de coqueiro anão.

\section{Resultados e Discussão}

Observou-se haver efeito significativo $(\mathrm{p}<0,01)$ nas doses de biofertilizante entre os tratamentos para a variável área foliar da planta na cultura do coqueiro anão verde. Conforme equações de regressão referente à área foliar da planta, o modelo ao qual os dados se ajustaram melhor foi o quadrático, indicando um coeficiente de determinação de 0,97. A medida em que se aplicava as doses crescentes de biofertilizante houve um aumento da área foliar da plante até um certo limite, a partir daí, apresentou um decréscimo da área foliar da planta no decorrer da fase fenológica da cultura. Conforme (Figura 1) percebe-se que a dose ótima foi de 1395,75 ml para a maior área foliar da planta de $889,12 \mathrm{~cm}^{2}$, provavelmente, essa redução da área foliar da planta pode está associada ao aumento acentuado da população de microrganismos no solo com o incremento da dose de biofertilizante, com aumento consequente do consumo de nutrientes, havendo, em consequência disto, redução da disponibilidade destes para as plantas (MALAVOLTA, VITTI \& OLIVEIRA, 1997).

Com relação aos efeitos da cobertura do solo (Figura 2), observa-se que os valores da área foliar da planta foram semelhantes na presença $(\mathrm{C} 1)$ e ausência $(\mathrm{C} 0)$ da cobertura do solo em plantas de coqueiro anão verde.

Figura 1. Efeitos de doses de biofertilizante sobre a altura de plantas.

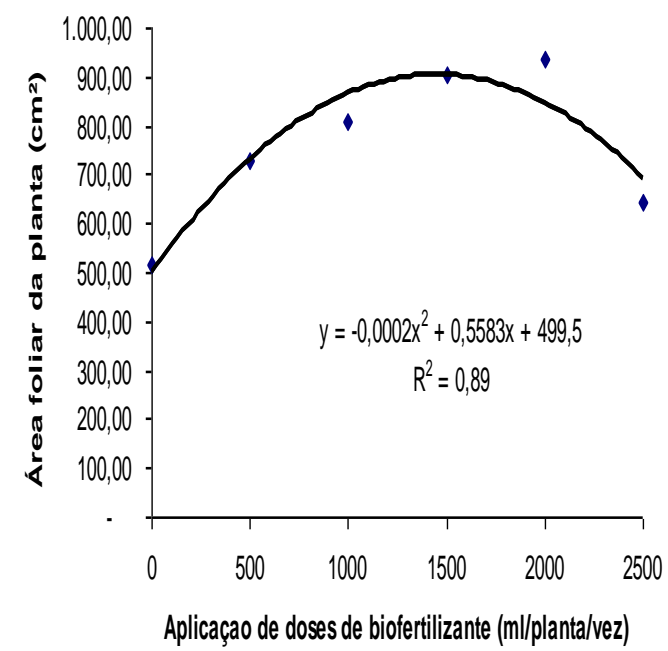

Figura 2. Efeitos de cobertura do solo sobre a altura de plantas.

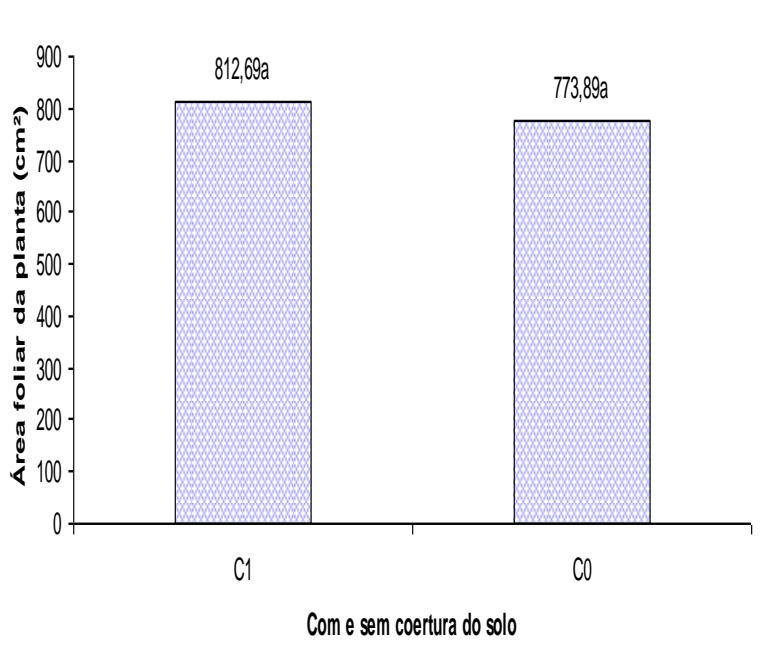


Conforme equações de regressão referente ao número de folíolos por folha, o modelo matemático que melhor se ajustou aos dados foi o linearmente decrescente. Observa-se que o número de folíolos por folha reduziu com o aumento de doses de biofertilizante, tendo havido reduçao de $-0,0054 \mathrm{ml}$ por aumento unitário da aplicação de doses de biofertilizante em número de folíolos por plantas de coqueiro anão verde orgânico (Figura 3), atingindo no nível máximo $\left(\mathrm{D}_{2}=500 \mathrm{ml}\right)$, um número máximo de folíolos por folha (72). Possivelmente esse declínio do número de folíolos por folha nos diferentes tratamentos, pode está associada ao aumento acentuado da população de microrganismos no solo com o incremento da dose de biofertilizante, com aumento consequente do consumo de nutrientes, havendo, em consequência disto, redução da disponibilidade destes para as plantas (MALAVOLTA, VITTI \& OLIVEIRA, 1997).

Os efeitos da cobertura do solo sobre o número de folíolos por folha de coqueiro anão verde não exerceram significância estatística (Figura 4), apresentando semelhança dos tratamentos com $\left(\mathrm{C}_{1}\right)$ e sem $\left(\mathrm{C}_{0}\right)$ cobertura do solo em plantas de coqueiro anão verde.

Figura 03. Aplicação de dosagens de biofertilizante na área foliar de plantas de coqueiro anão.

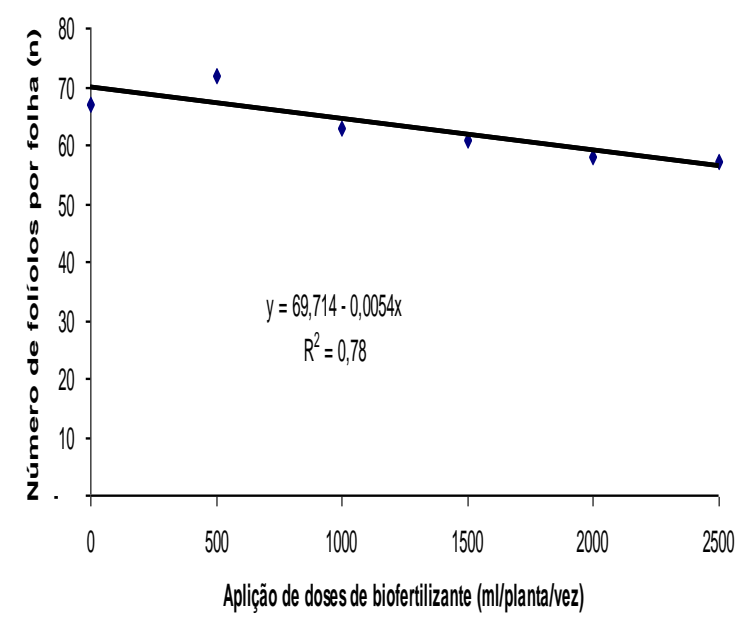

Figura 04. Aplicação de substratos na área foliar de plantas de couqeiro anão.

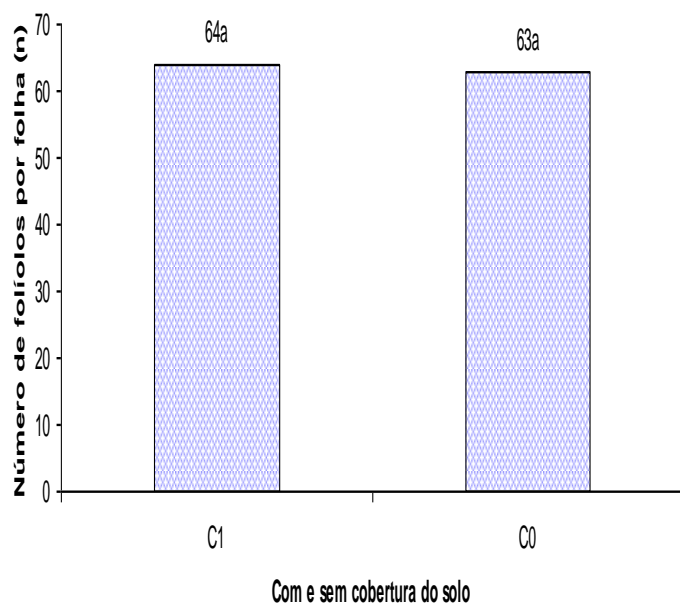

\section{Conclusões}

A área foliar da planta obteve uma dose ótima de de 1395,75 ml para a maior área foliar da planta de $889,12 \mathrm{~cm}^{2} / \mathrm{vez}$

As doses de biofertilizante afetaram de forma significativamente decrescente o número de folíolos por folha 
A cobertura do solo obteve uma semelhança para os tratamentos entre si das variáveis área foliar da planta e número de folíolos por folhas.

\section{Referências}

AGRIANUAL 2008: anuário da agricultura brasileira. Coco-da-baía. São Paulo: FNP, Consultoria e agroinformatifos, 2008. 304-310 p.

BORGES, M. ;BETTIOL, W. Embrapa Meio Ambiente. Agricultura OrgânicaInformativo- ano $V n^{0} 17$. jan/fev/mar. 1997.

DAROLT, M. R. Agricultura orgânica, inventando o futuro. Londrina: IAPAR, 2002, 250p.

MALAVOLTA, E.; VITTI, G.C.; OLIVEIRA, S.A. de. Avaliação do estado nutricional das plantas: princípios e aplicações. 2.ed. Piracicaba: POTAFOS, 1997. $319 \mathrm{p}$.

SOUZA, J. L.; RESENDE, P. Manual de horticultura orgânica. $2^{\text {a }}$ ed. Viçosa: Aprenda Fácil, 2006. 843p.

VIDAL, R.A.; BAUMAN, T. Efeito de níveis de palha de trigo no microclima do solo sob plantio direto. In: CONGRESSO BRASILEIRO DE PLANTIO DIRETO PARA UMA AGRICULTURA SUSTENTÁVEL, 1., Ponta Grossa, PR, 1996. P.118-20. 